\title{
ARQUITETURA EM UNIDADES DE CONSERVAÇÃO: PROPOSTAS DE ORGANIZAÇÃO ESPACIAL PARA O PARQUE BOTÂNICO DO MORRO DO BAÚ - SC
}

\author{
ARCHITECTURE IN CONSERVATION UNITIES: IDEAS OF BETTER SPACE ORGANIZATION \\ FOR THE "PARQUE BOTÂNICO DO MORRO DO BAÚ"
}

\section{REIS, Almir Francisco}

Arquiteto urbanista, Professor do Departamento de Arquitetura e Urbanismo da UFSC - Doutor pela Faculdade de Arquitetura e Urbanismo da Universidade de São Paulo. E-mail: almir@arq.ufsc.br

\section{ELY, Vera Helena Moro Bins}

Arquiteta urbanista, Professora do Departamento de Arquitetura e Urbanismo da UFSC, Tutora do grupo PET/ARQ/UFSC (Programa de Ensino Tutorial) - Doutora em Engenharia de Produção - UFSC e UCL (Université Catholique de Louvain). E-mail: vera@arq.ufsc.br

\section{SOUZA, Fabíola Bernardes}

Acadêmica do curso de Arquitetura e Urbanismo da UFSC, bolsista do grupo PET/ARQ/UFSC (Programa de Ensino Tutorial).E-mail: fabiolabs@gmail.com

\section{BUBNIAK, Fábio}

Acadêmico do curso de Arquitetura e Urbanismo da UFSC, bolsista do grupo PET/ARQ/UFSC (Programa de Ensino Tutorial).E-mail: arquitetofabiobubniak@yahoo.com.br

\section{RESUMO}

O objetivo deste trabalho é refletir sobre a organização espacial em unidades de conservação, bem como sobre os conceitos e métodos para a inserção de arquitetura em áreas legalmente protegidas. Ilustrando essa discussão, apresenta-se o lançamento inicial de idéias, visando uma melhor organização espacial para Parque Botânico do Morro do Baú - unidade de conservação situada no estado de Santa Catarina.

Estas idéias estão pautadas na pesquisa "Arquitetura em Unidades de Conservação: Critérios para implementação de elementos construídos no Parque Botânico do Morro do Baú", realizada pelos autores. Nesta pesquisa, elaborou-se um diagnóstico da situação atual do Parque Botânico do Morro do Baú, a partir do qual, tornou-se possível a elaboração de estudos de planejamento ambiental, buscando a qualificação da sua estrutura de visitação pública, que atualmente, não oferece condições para que o visitante tenha a oportunidade de interar-se com os reais objetivos conservacionistas do parque, levando, muitas vezes, a degradação de seu patrimônio natural e cultural.

\section{Palavras-chave: Unidades de conservação, parques e áreas de visitação.}

\begin{abstract}
The main objective of this work is to reflect on space organization in Conservation Unities, and how building concepts and equipment can improve the visitors conception of the environment. Initial ideas of better space organization for the "Parque Botânico do Morro do Baú" - a Conservation Unity located in the State of Santa Catarina - are presented.

These ideas are based on the research "Arquitetura em Unidades de Conservação: critérios para implementação de elementos construídos no Parque Botânico do Morro do Baú", already implemented by the authors. From this research, an updated diagnosis of the "Parque Botânico do Morro do Baú", was analysed, from which was possible to elaborate an environmental planning study for it. This study has recognized the inadequate structure of public visitation, which is spoiling the opportunity the visitor has to understand and be in contact with the true conservation objectives of the park, and as a result, degrading its natural and cultural patrimony.
\end{abstract}

Key words: Conservation unities, parks, visiting areas. 


\title{
Introdução
}

Já faz algum tempo que a humanidade assiste a uma aceleração da destruição imposta à diversidade biológica do planeta. Como forma de defender o meio-ambiente têm sido estabelecidas unidades de conservação, áreas legalmente protegidas por uma legislação específica e com o seu uso direcionado à conservação.

A criação de unidades de conservação é algo louvável. Contudo, para que sua implementação seja realmente eficiente, é evidente que sua criação deve ser o resultado de estudos sérios, onde não haja erros quanto à escolha da categoria da área nem de sua delimitação. É fundamental a existência de uma administração e de uma gestão adequadas, pautadas num plano de manejo.

Os planos de manejo para unidades de conservação, constituem documentos elaborados por grupos interdisciplinares que visam a orientação de intervenções na unidade, evitando equívocos que impliquem em reações contrárias à da conservação, podendo ser definidos como:

\begin{abstract}
"(...) instrumentos voltados à preservação e conservação dos recursos naturais, bem como, ao uso desses recursos para pesquisa científica e para visitação pública na forma de ecoturismo e educação ambiental, dentro de espaços pré-estabelecidos por um documento legal. Procura-se assegurar a manutenção do potencial dos elementos naturais em detrimento de demandas, a conservação em detrimento do uso ou manejo abusivo e a participação da comunidade, além de garantir obediência a padrões legais ambientais". (SANTOS, 2004, p.38).
\end{abstract}

O profissional arquiteto-urbanista, auxiliado por um plano de manejo, tem um papel fundamental no sentido de colaborar na organização espacial de áreas de conservação em zonas, com seus respectivos graus de proteção e intervenção, de acordo com suas finalidades.

Com essa preocupação, a qualidade da visitação aparece como um dos itens fundamentais no processo de planejamento de uma unidade de conservação. As áreas destinadas à visitação pública são importantes pois, bem qualificadas, possibilitam que o visitante incorpore informações ambientais, compreendendo o significado da unidade de conservação e a importância de se preservar a natureza.

Este artigo é o resultado de um trabalho de pesquisa, realizado pelo grupo PET/ARQ/UFSC (Programa de Ensino Tutorial do Curso de Arquitetura e Urbanismo da UFSC), cujo título é: "Arquitetura em Unidades de Conservação: Critérios para implementação de elementos construídos no Parque Botânico do Morro do Baú". Neste trabalho, fez-se um diagnóstico da situação atual do parque, que tornou possível a elaboração de estudos de planejamento ambiental, visando a qualificação da sua estrutura de visitação pública.

\section{O parque botânico do Morro do Baú}

O Parque Botânico do Morro do Baú, situado no estado de Santa Catarina, é uma Unidade de Conservação administrada pelo Herbário Barbosa Rodrigues, centro de pesquisa botânica e ambiental de reconhecimento mundial. O parque conta com 750 hectares e apresenta expressiva área de mata primária, caracterizando-se pelo potencial paisagístico inerente ao maciço que Ihe atribui o nome (o Morro do Baú). Estas características têm atraído um expressivo contingente

126 de visitantes na busca das práticas de lazer e recreação, atividades concomitantes às pesquisas científicas da unidade de conservação.

A diversificação de usos e atividades decorrentes tem configurando conflitos relacionados ao acolhimento e controle da visitação pública. A falta de uma infraestrutura de apoio adequada 
a essa visitação, bem como fiscalização e normas claras para sua realização, tem levado a atitudes incompatíveis com os ideais de preservação. Além disto o visitante não tem oportunidade de interar-se com os reais objetivos conservacionistas do parque, tornando-se, freqüentemente, apenas um consumidor e degradador dos atrativos naturais da área.

\section{Objetivo}

O trabalho tem como objetivo refletir sobre a organização espacial em unidades de conservação, bem como sobre os conceitos de arquitetura para essas áreas legalmente protegidas. Ilustrando essa discussão, apresenta-se o lançamento de idéia visando uma melhor organização espacial para Parque Botânico do Morro do Baú.

Outro aspecto importante é o fato do trabalho ter oportunizado a estudantes da graduação contato com unidades de conservação, uma vez que esta, ainda, não é uma escala devidamente estudada dentro das escolas de Arquitetura e Urbanismo, caracterizando-se, portanto, como um tema complementar na sua formação, em especial ao que tange à questão ambiental, hoje fundamental para o arquiteto-urbanista. Neste sentido, enfatiza-se que este foi um trabalho interdisciplinar que contou, também, com a assessoria do biólogo e professor, responsável pela administração do parque em estudo, Dr. Ademir Reis.

\section{Métodos}

Na pesquisa realizada pelos autores, além da busca por referências bibliográficas acerca das unidades de conservação e suas implicações e da realização de visitas ao parque, julgou-se imprescindível os estudos de similares, visando a compreensão do funcionamento da área destinada à visitação pública de uma unidade de conservação.

Assim, estudaram-se os locais de visitação pública e respectivos equipamentos de duas unidades de conservação de Florianópolis, localizadas na llha de Santa Catarina: o Parque Municipal da Lagoa do Peri e o Parque Florestal do Rio Vermelho, e de uma unidade de conservação do Estado do Paraná, localizada nas proximidades do município de Guaraqueçaba e considerada referência internacional, a Reserva Natural Salto Morato.

Por fim, formulou-se um diagnóstico da situação atual Parque Botânico do Morro do Baú, o qual, junto aos estudos de similares, permitiu ao grupo adquirir subsídios para a elaboração de estudos de planejamento ambiental, visando a qualificação da sua estrutura de visitação pública.

Entende-se por planejamento ambiental:

"(...) O planejamento das ações humanas (da antropização) no território, levando em conta a capacidade de sustenção dos ecossistemas a nível local e regional (...) visando a melhora da qualidade de vida humana, dentro de uma ética ecológica". (FRANCO, 2001, p.36-37)

De acordo com FRANCO (2001, p.36 - 37) o Planejamento ambiental pode, também, ser considerado um Planejamento Territorial Estratégico, Econômico-ecológico, Sócio-cultural, Agrícola e Paisagístico. Ainda neste contexto, são entendidos três princípios de ações humanas sobre o ecossistema: os princípios de preservação, da recuperação e da conservação do meio ambiente.

artigo divide-se em duas partes fundamentais. A primeira, abrange brevemente conceitos gerais sobre Arquitetura em unidades de conservação. Já na segunda, apresenta-se a prática projetual realizada na área destinada à visitação pública do Parque Botânico do Morro do Baú. 


\section{Arquitetura em unidades de conservação}

O processo de concepção de elementos construídos em unidades de conservação é um momento importante para a elaboração da chamada "arquitetura ecológica", a qual de acordo com Costa (apud Hardt, 2000, p. 23) pode ser conceituada como, a "arte de construir edificações aproveitando (...) apenas os recursos imediatos propiciados pela própria natureza, sem alterar o equilíbrio ecológico da mesma" e mesmo da "arquitetura bioclimática", ou seja:

"O conjunto de soluções projetuais que permite que num mesmo edifício sejam asseguradas as condições de bem -estar utilizando o menos possível instalações que exijam consumos energéticos de fontes exauríveis. É preciso que o edifício determine uma relação com o ambiente exterior capaz de produzir as necessárias alterações de condições ambientais, sobretudo em virtude das suas características (morfológicas, termofísicas, dimensionais,...)". (ENEA \& IN/ARCH apud Hardt, 2000, p. 23).

Segundo Hardt (2000, p. 16), a concepção dos elementos construídos em uma unidade de conservação pode ser considerada em dois momentos: estudos de conjunto e estudos individuais.

Nos estudos de conjunto, as estruturas construídas devem atender algumas condicionantes, sendo a capacidade de carga uma delas. Esta condicionante está relacionada a quantidade de uso que pode ser mantida em um tempo específico, sem causar danos ao patrimônio natural da unidade de conservação. Há que se pensar no limite aceitável de visitação e nos tipos de atividades que serão desenvolvidas em determinadas áreas. Enfim, deve-se compreender a unidade como um todo, para que sejam evitados conflitos entre os diversos usos do local, visando tanto o bem estar dos visitantes quanto a proteção dos recursos naturais.

Com relação à análise individual, a arquitetura em UCs, deve ser pensada de modo a estar em harmonia tanto com o meio e com as condicionantes ambientais, funcionais e conceituais, quanto com as tecnologias necessárias para a sua concepção.

Conforme (Muller apud Hardt, 2000, p. 17) na idealização de qualquer elemento construído dentro de uma unidade de conservação, a orientação das atividades do planejador deverá estar voltada para a preservação e intensificação das características naturais da área protegida, evitando, o rompimento da integridade da paisagem, estabelecendo harmonia com o ambiente pré-existente.

Outro aspecto importante a se considerar, é a análise das limitações do ambiente. Afinal, o clima é determinante das características de conforto ambiental - térmico, acústico, de ventilação e luminosidade - de edificações. Soma-se a isto, o cuidado com as drenagens naturais, com a possibilidade de contaminação dos lençóis freáticos, com as características da topografia, fauna e flora. Não se pode perder de vista, também, a adequação funcional do elemento construído.

$\mathrm{Na}$ concepção de edificações, instalações e elementos de comunicação visual, são muito importantes as questões relacionadas à forma e à função. Na verdade, as edificações em áreas protegidas, não necessariamente precisam comportar-se como simples construções, e nem devem. A forma de uma obra arquitetônica deve sim, buscar uma identidade e possuir um "caráter", expressando claramente a função que desempenha enquanto peça fundamental na organização espacial de uma unidade de conservação.

Quanto ao sistema de circulação bem como, ao traçado das vias de acesso, deve-se possibilitar ao visitante contato com uma variedade de paisagens e de recursos naturais expressivos do lugar. É importante, também, que se restrinja o uso do automóvel no interior da unidade de conservação, de modo a facilitar a fiscalização e a proteção dos elementos naturais e culturais 
da área. Além disso, não se pode esquecer de soluções projetuais que facilitem a acessibilidade de portadores de deficiências físicas, cognitivas e/ou sensoriais, oportunizando a todos momentos especiais de contato com a natureza.

\section{Propostas de organização espacial para o Parque Botânico do Morro do Baú}

Com o intuito de identificar de forma mais concisa os problemas do parque foram realizadas algumas visitas ao local, que complementaram as outras atividades realizadas: estudos de similares, entrevistas com gestores do parque e pesquisa bibliográfica. Nessas visitas foram elaborados levantamentos arquitetônicos expeditos e fotográficos, obtendo-se um vasto material, entre croquis e imagens da área. Foi também confeccionada uma maquete da área do parque, a qual passou a ser utilizada como instrumento de trabalho do grupo em todas as suas visitas a campo, enriquecendo a apropriação e a compreensão da área de estudo (FIGURAS 1e 2).

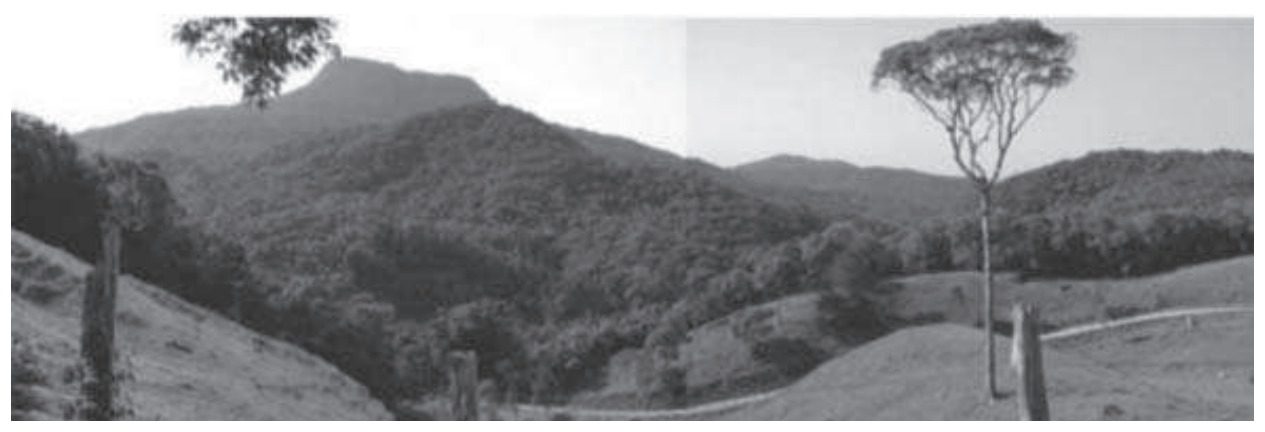

Figura 1: Vista parcial do parque. Ao fundo, o Morro do Baú Fonte: Autores, 2004

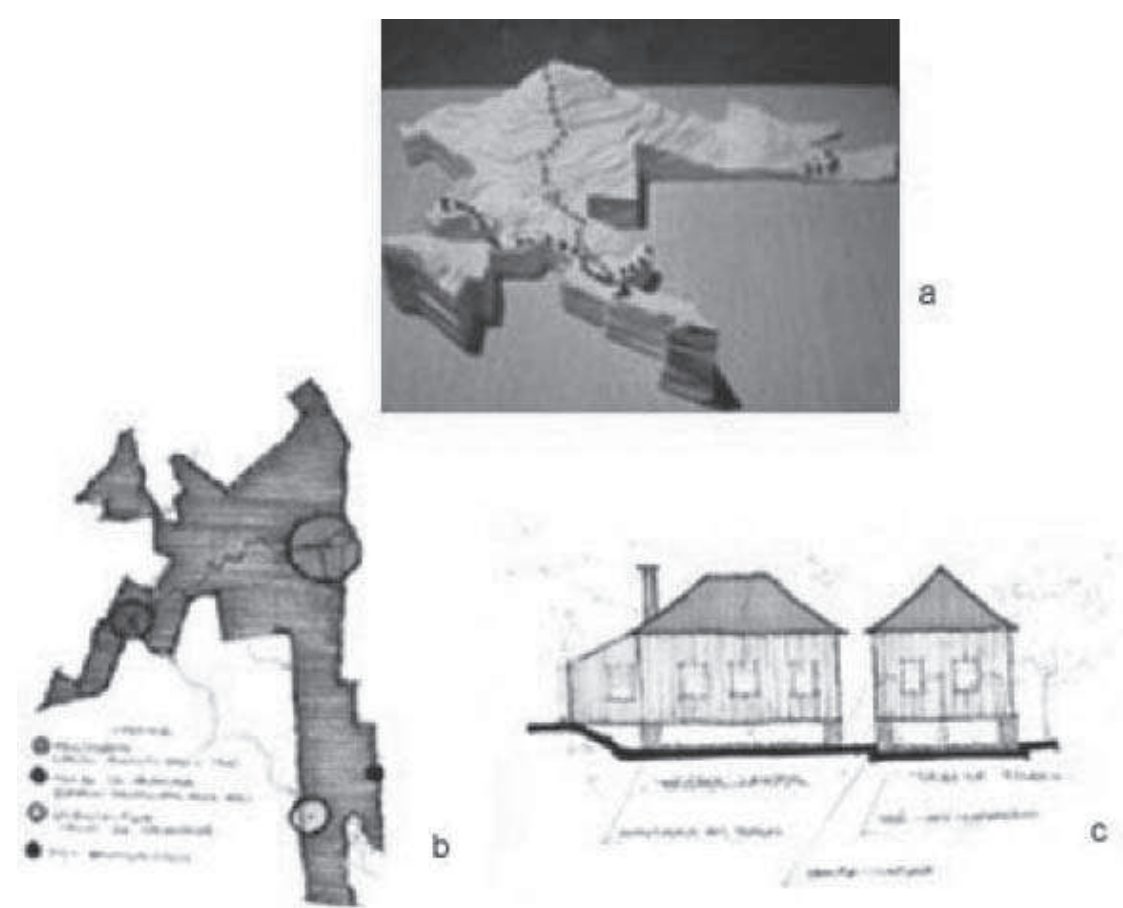

Figura 2: a) maquete de estudos; b) croqui de estudo da área do parque; c) croqui de edificação existente no parque Fonte: Autores, 2004

As análises realizadas permitiram um diagnóstico inicial da situação, onde aliado às potencialidades e atrativos naturais da unidade de conservação, foram levantadas as deficiências existentes em termos de visitação pública e do trato com a paisagem. 
Acredita-se que uma melhor estruturação da área destinada à visitação pública do parque, traria benefícios não somente ao parque, como também às áreas próximas, contribuindo na minimização dos impactos ambientais e melhorando a qualidade de vida das pessoas.

De modo a tornar a análise mais objetiva e legível, buscou-se classificar os problemas detectados em quatro itens: orientação (sinalização e informação), limites, acessos e infra-estrutura. Esses itens serão abordados a seguir, juntamente com as propostas sugeridas para os problemas detectados (FIG. 3).

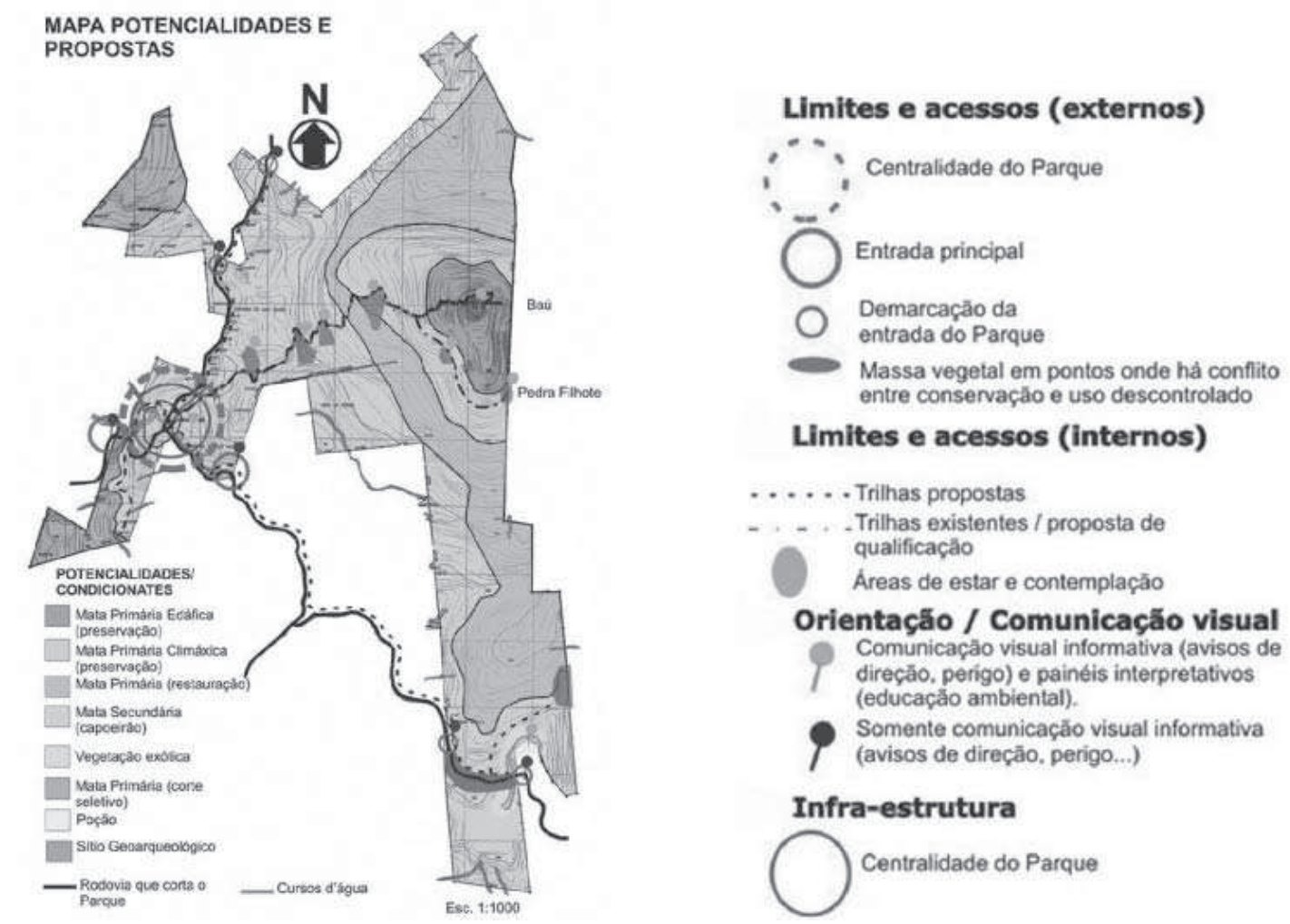

Figura 3: Mapa do Morro do Baú - Potencialidades e propostas Fonte: ZIMMERMANN, 2000, alterado pelos autores, 2005

\section{Orientação e comunicação visual}

A busca por um sistema de comunicação é tão importante quanto à delimitação da área ou mesmo quanto à restrição de acessos, uma vez que pode ajudar no sucesso destes últimos, orientando e indicando os locais e ações permitidas na área.

Constatou-se que na área de visitação do parque, não existe uma coerência de conjunto, o que torna a informação obtida no lugar de difícil percepção, dificultando a orientabilidade dos visitantes e impedindo-os de compreender espacialmente o lugar. A carência de informações relacionadas à configuração espacial das edificações existentes, somada às deficientes informações gráfica, faz com que o parque acabe se utilizando quase que exclusivamente da comunicação verbal e dos referenciais naturais.

Sentiu-se falta, também, de informações para a devida interpretação ambiental, traduzindo o significado do patrimônio natural e cultural da unidade de conservação para a linguagem comum dos visitantes. Esta informação pode ser diluída por todo o parque, na forma de placas, totens, pórticos, publicações, exposições audiovisuais, etc. Neste momento, dois grupos de elementos informativos são importantes. O primeiro caracterizado por uma comunicação visual informativa que visa a orientação espacial dos visitantes, estabelecendo as ações permitidas ou não dentro 
da área. O segundo contendo as informações que busquem despertar a consciência ecológica, mostrando e explicando a fauna e flora, existentes no parque.

Dentro desse contexto, foram elaboradas diretrizes, no sentido da formulação de um sistema global de informações para o parque, bem como especuladas propostas de sua materialização (FIG. 4)

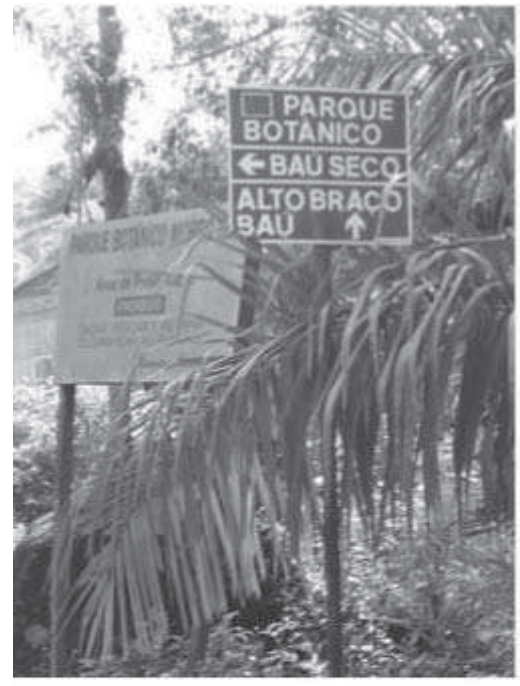

a

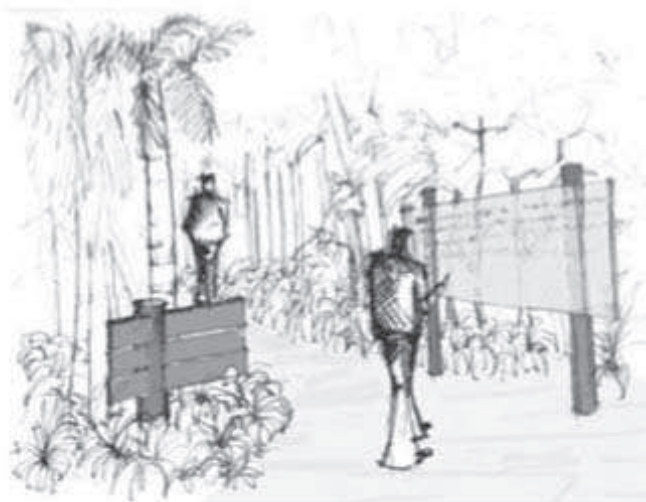

b

Figura 4: a) imagens das placas existentes no parque ; b) croqui sugerindo a comunicação visual das trilhas Fonte: autores, 2004-2005

\section{Limites e acessos externos}

A passagem da estrada estadual que corta todo o parque, bem como as várias possibilidades de acesso acabam por dificultar a fiscalização, deixando-o muitas vezes suscetível a ações contrárias a da conservação.

A primeira solução encontrada, talvez a mais expressiva em termos de acesso ao parque, é a demarcação das suas entradas. Sugere-se a implantação, em dois pontos (FIG. 3), de marcos especiais, que indiquem a chegada à centralidade do parque. Essa entrada deve ter um trato especial tendo em vista sua importância na orientação dos visitantes, e conseqüentemente no controle das atividades desenvolvidas no interior da unidade. (FIG. 5).

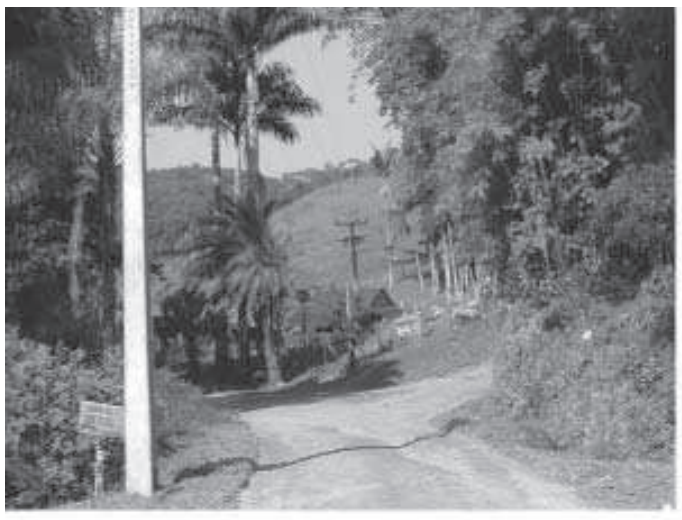

a

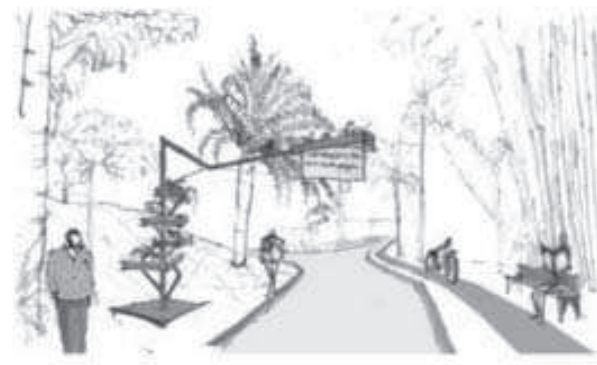

b

Figura 5: a) imagem da entrada principal do parque; b) croqui sugerindo a demarcação dessa entrada principal Fonte: Autores, 2004-2005 
As demais demarcações de acesso ao parque propostas, além de anunciarem aos usuários a passagem pelo interior do parque, alertam sobre as ações compatíveis com a preservação do local.

Acredita-se que a introdução de cortina vegetal, configurada por vegetação arbustiva, em pontos onde há conflitos entre uso descontrolado e a conservação, delimita as áreas propícias à utilização e pode resguardar aquelas destinadas à preservação. Esses conflitos são propiciados pela passagem da rodovia que corta o parque em vários momentos, como pode se observar na FIG. 3.

\section{Limites e acessos internos}

A falta de estruturação das trilhas existentes, no sentido de permitir a abordagem interpretativa na educação ambiental, caracteriza-se como um problema a ser solucionado. No parque, existem cinco trilhas ecológicas destinadas ao uso público que levam aos seus principais atrativos paisagísticos: a Cachoeira Véu de Noiva, a Pedra "Filhote", o topo do Morro do Baú, um importante conjunto geo-arqueológico, e outros pontos de desfrute da natureza, propiciados por associação entre vegetação natural, características geo-morfológicas e cursos d'água.

A idéia principal é o enriquecimento das trilhas já existentes e a criação de outras, sempre se aproveitando da comunicação visual e visando o aproveitamento de recursos significativos em termos paisagísticos e ambientais, para que então se garanta uma eficiente educação ambiental e conseqüentemente a proteção da natureza.

Na trilha que leva ao Morro do Baú, por exemplo, o uso de painéis interpretativos que indiquem os tipos de vegetação (Mata Primária, Mata Secundária e Vegetação Exótica), sobre os quais a trilha passa, surgem como uma forma de enriquecer o percurso. No ponto final desta trilha, no topo do Morro do Baú, onde for viável, a instalação de um grande mirante é algo louvável, uma vez que permitirá a visualização de uma grande fatia do litoral catarinense e do Vale do Rio Itajaí-Açú.

Propõe-se, a criação de uma trilha paralela à rodovia, partindo da centralidade do parque e que passe pelas residências da população local. Além de ser uma forma de delimitar o parque, esta trilha tem como objetivo integrar a população vizinha, em uma possibilidade de ecoturismo sustentável a partir da venda de produtos artesanais, doces, frutas, etc.

\section{Infra-estrutura}

Com relação à infra-estrutura, notou-se a inexistência de uma área de recepção aos visitantes, que informe e organize o processo de visitação, apresentando informações acerca do parque, sua estrutura, seus objetivos, suas potencialidades ambientais e paisagísticas.

A consolidação de uma centralidade para o parque (FIG. 3) torna-se essencial no sentido de caracterizar um ponto de partida e chegada das atividades ali desenvolvidas. Soma-se a isto, a criação de uma referência forte em termos de localização, constituindo um espaço específico organizado próximo ao acesso principal, sob a forma de um centro de visitantes. Acredita-se que a localização mais apropriada para esta centralidade, é o local onde atualmente se encontram edificações e instalações de apoio às ações que o parque permite e proporciona aos seus usuários.

132 Além disso, percebeu-se a sub-utilização de algumas edificações históricas existentes que remontam ao passado agrícola-colonial da área. Recicladas, podem abrigar novos usos que ressaltem seu valor patrimonial e ainda, podem ser utilizadas pela unidade para disseminar educação ambiental, possuindo em seu interior espaços de apoio aos visitantes (FIG. 6). A idéia é utilizá- 
la como o centro de recepção e informação, onde os visitantes poderão ter a oportunidade de compreender a história do parque bem como sua importância.
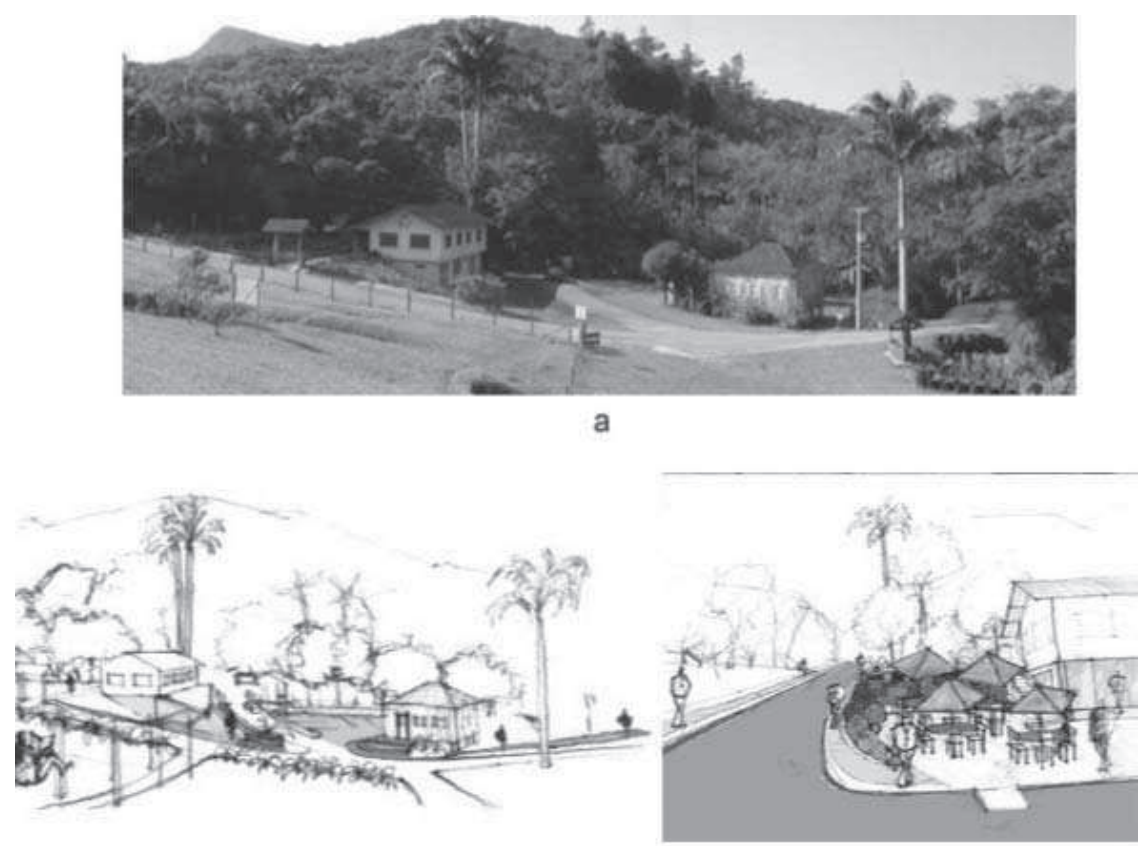

b

Figura 6: a) Imagem das edificações do parque; b) croquis propondo reciclagem das edificações Fonte: Autores, 2004-2005

São evidentes, as deficiências da área de camping, no sentido de acomodar os campistas e a visível degradação dos equipamentos de apoio, bem como conflito em sua localização, na medida em que se encontra numa área de interesse paisagístico no contexto do parque. Propõe-se a relocação desta atividade para uma outra área, de menor importância paisagística e ambiental (FIG. 7) com projeto definitivo ainda a realizar-se, atentando para a necessidade de estudo de adaptação topográfica.

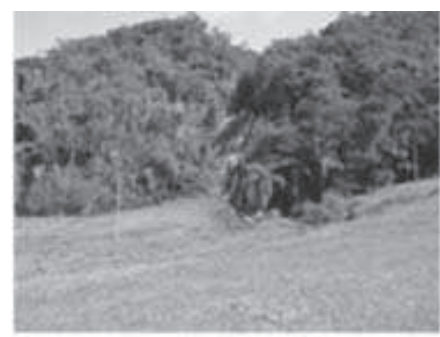

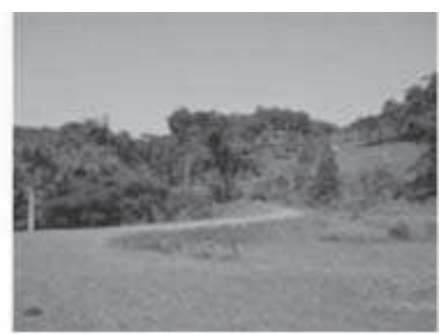

b

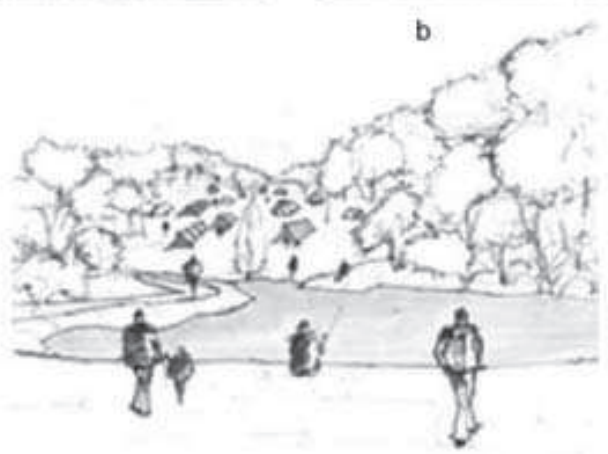

c

Figura 7: a) vista da cachoeira e açude esvaziado; b) croqui propondo nova localização do camping e restauração do açude

Fonte: Autores, 2004-2005 
Para a atual área do camping, onde a cachoeira existente ajuda a transformá-la num dos lugares mais interessantes da unidade, pensa-se em uma edificação discreta que não concorra com a natureza exuberante do local. É importante, que essa edificação possua um baixo consumo de energia, tirando proveito da ventilação natural, por exemplo, tentando mitigar o impacto no meio ambiente. Sutilmente acomodada na topografia do lugar, propõe-se, que essa edificação se integre ao açude, hoje esvaziado, a ser restaurado (FIG. 7). Seus usos estarão pautados em atividades predominantemente de educação ambiental, como auditório, espaços para oficinas, salas expositivas, refeitório, entre outros.

\section{Considerações finais}

O planejamento e a gestão de uma unidade de conservação, constituindo um trabalho interdisciplinar, deve incorporar conhecimentos de diversas áreas. Especificamente nas questões do trato com o espaço físico, tais preocupações trazem à cena diferentes possibilidades de atuação do profissional arquiteto. Dentre essas atuações, tem-se a inserção desse profissional junto a equipes multidisciplinares responsáveis pelo planejamento global e pela elaboração de planos de manejo. Soma-se a isto, ações no sentido de qualificar a infra-estrutura de áreas protegidas, através da concepção de edificações e equipamentos, da qualificação de caminhos e trilhas ou da formulação de sistemas de informação e comunicação visual.

No caso do parque estudado, concluiu-se que a falta de um plano de manejo reflete-se numa inadequada infra-estrutura de visitação pública. Acredita-se que uma melhor estruturação dessas áreas, além de tornar a unidade de conservação mais atrativa e propícia às atividades de pesquisa e recreação, se aproximaria do ideal de um planejamento sustentável.

Contudo, não basta apenas ter uma organização espacial eficiente constituída por edificações interessantes, sem que não se tenha clara a delimitação da unidade de conservação. Deve-se entender, também, que a fiscalização e a contratação de funcionários qualificados, constituem premissas fundamentais para a qualificação da área de visitação do Parque Botânico do Morro do Baú.

O lançamento de idéias e propostas aqui apresentado visa a maximização das potencialidades naturais do lugar, sem perder de vista a educação ambiental. A conservação do sítio e conseqüentemente da memória e cultura local tornam-se, as principais condicionantes na composição da paisagem proposta. É importante compreender a relação, dos espaços criados ou modificados, com os elementos da paisagem existente, para que de fato, esse parque se constitua como um local saudável e de intercâmbio entre o homem e a natureza.

\section{Bibliografia}

FRANCO, Maria de Assunção Ribeiro. Planejamento ambiental para a cidade sustentável. São Paulo: Annablume/ Fapesp, 2001.

MILANO, Miguel Sereduik (Org.). Unidades de conservação: Atualidades e tendências. Fundação O Boticário de Proteção à Natureza, 2002.

HARDT, Letícia Peret Antunes. Fundamentos técnicos: Concepção de elementos construídos em unidades de conservação. Curitiba: Universidade Livre do Meio Ambiente, 2000.

SANTOS, Rosely Ferreira dos. Planejamento ambiental: Teoria e prática. São Paulo: Oficina de textos, 2004.

ZIMMERMANN, Carlos Eduardo. Dispersão da Virola vicuhyba (sehott) Warb. no Parque Botânico do Morro do Baú, de Santa Catarina, Florianópolis, 2000. 